\title{
The Appropriate Mode in the Application of the Philosophy of Sufficiency Economy in the Environmental Management of the Industrial Sector
}

\author{
Wisakha Phoochinda, Ph.D. \\ Graduate School of Social and Environmental Development, National Institute of Development Administration (NIDA), \\ Bangkok, 10240, Thailand
}

\begin{abstract}
This study aims to investigate success in the application of sufficiency economy philosophy of industries, to investigate factors affecting the application in environmental management and to suggest appropriate mode. Data are collected using in-depth interviews with nine businesses successfully applied the philosophy; a questionnaire surveying on samples of $\mathbf{4 0 0}$ factories; and in-depth interviews with three businesses surveyed, interested in applying the philosophy. According to in-depth interviews of the nine businesses, success in the application depends on e.g. social awareness, management's vision and policy, faith in the philosophy, knowledge and understanding of the philosophy. Factors contributing to the application in environmental management from the questionnaire are the size of the industry, policy on environmental management, access to information, opinion on the application and participation in activities involving the application. Appropriate mode in the application involves management, staff involvement, the faith in the philosophy as well as knowledge and understanding of the philosophy.
\end{abstract}

Keywords-philosophy of sufficiency economy; environmental management; business and industrial sectors.

\section{INTRODUCTION}

Nowadays the problems concerning natural resources and environment are aggravating. Natural resources have been heavily exploited in a remiss and inefficient manner and thus may soon be finally used up. The environment has been polluted. The main factor is of course humans, whose exploitation of the natural resources in their daily lives be it business, transportation, production or industry, as well as other activities; have subsequently affected the environment adversely. With more awareness of the problems, the industrial sectors nowadays have implemented various techniques in dealing with them, for example reuse and recycle, value engineering, energy saving in order to cut down on the use of materials and natural resources and for the sustainability of the business. Several environmentally friendly products are now on the market, for example electrical appliances with the green label, which reflects that the industrial sector cares more for the environment. A business will be able to continue only if the public and the consumers support it. In this way, social responsibility is very important.

The philosophy of sufficiency economy, which is avidly implemented and supported by His Majesty the King Bhumibol, can be applicable to the way people lead their life at all levels, be it in their family, community, and state. The focus of this philosophy is on moderation and step-bystep development. In agriculture, the philosophy has paved way to the 'New Theory of Agriculture'. In the industrial sector, it has been successfully applied in many small-scale and middle-scale industries. Nowadays large-scale businesses and industries have already initiated applying this philosophy in their practice, though not yet extensively. In applying the philosophy of sufficiency economy in the environmental management, involved are three concerns moderation, sensibility, and immunity; as well as two conditions - knowledge and integrity. Efficient environmental management will lead to sustainability through careful treatment of the environment and wise and efficient use of the natural resources, as well as innovation in finding alternative sources for future use, all of which are in line with the three concerns and two conditions aforementioned.

The investigation of the appropriate modes in the environmental management of the industrial sector based on the philosophy of sufficiency economy is of interest, for it can set an example for other industries and sectors, and provide the insight into the factors contributing to the decision to apply this philosophy to the environmental management of the industrial sector. In this way, the most appropriate mode can be finalized, which can serve as a model for practical implementation. Decreased pollutions and efficient and economical use of natural resources can definitely contribute to a better society with sustainable development and balance, be it economically, socially, or environmentally.

The objectives of this study are to investigate the application of the philosophy of sufficiency economy in the environmental management of the industrial and business sectors and the factors contributing to the application and to find the appropriate mode of application of the philosophy of sufficiency economy in the environmental management and the relevant activities of the industrial and business sectors.

\section{RESEARCH METHODOLOGY}

Data are collected using in-depth interviews with the personnel in charge of the sufficiency economy of altogether nine companies and factories, all of which can boast success, either certified or widely recognized, in terms of the application thereof, in order to find out about 
their experience and factors leading to such success. A questionnaire surveying on the target sample group of 400 manufacturing factories all over the country is used to find out about the factors leading to the decision to apply this philosophy in their various activities and environmental management. The analysis of the data from the aforementioned interviews and questionnaire is then used to devise an appropriate mode in the application of the philosophy of sufficiency economy to experiment on three companies or factories interested in effectively implementing it.

The target group and key informant:

1) Factories or businesses which have successfully applied the philosophy of sufficiency economy in their environmental management and been awarded. The selection of the factories or businesses to investigate is based on their size or scope of their business. As a result, three small-scale, three middle-scale, and three large-scale operators; altogether nine are selected and then in-depth interviews with the personnel in charge of the implementation of sufficiency economy of their businesses are carried out.

2) There are 457,968 type $D$ factories or manufacturing businesses, of categories 15 - 37 (altogether 22 categories), according to the Industrial Census of 2007, the National Statistics Office. The sample size is calculated using the Yamane formula and then four hundred factories are sampled. Within the sample group of 400, stratified sampling is applied. The 22 categories of industries are separated into four groups based on similarity - the food product group, the other consumer products group, the heavy industry group, and the other types of industries group. Then quota sampling is applied, so there are 100 samples in each four groups. Finally, random sampling using the simple method is used to select all the subjects.

3) Three factories surveyed through the questionnaire which are interested in implementing projects or activities related to the application of the philosophy of sufficiency economy.

In this study data are collected both quantitatively and qualitatively. The tools employed include the questions in the interviews of factories or companies successful in the application of the philosophy of sufficiency economy, the questionnaire used with type $\mathrm{D}$ factories and the questions in the interviews of the factories or companies surveyed which are interested in applying the philosophy to probe on the appropriate mode.

\section{RESEARCH FINDINGS}

In this study, factors contributing to the success of the companies or factories having applied the philosophy of sufficiency economy in their environmental management and factors contributing to the decision to apply the philosophy of sufficiency economy of the factories surveyed in the sample group are investigated. The results from the two sources then are analyzed to investigate the appropriate mode in the application of the philosophy of sufficiency economy in the environmental management.
A. Factors contributing to the success of factories having applied the philosophy of sufficiency economy in their environmental management are analyzed through the method of grouping the factors leading to the success according to CIPP model theory developed by Stufflebeam (1983) [1]. The analysis of the interviews reveals that the most important factors leading to successful application of the philosophy of sufficiency economy are internal factors, which are as follows according to their order of importance.

- Social concern: that the organization is concerned about the well being of the society.

-Vision and policy of the management: the management is aware of the importance of and has put the philosophy into practice as well as has introduced it to the operational level in a regular and continuous manner.

- Faith that the management and staff have in the philosophy: that it will lead to success which is both beneficial to the organization and themselves.

- Proper knowledge and understanding of the philosophy: as these will lead to the right attitude and proper behavior in the application thereof.

-The use of the philosophy as a performance indicator: this will help leading to purposeful implementation among the staff. According to the interview, successful businesses use the philosophy as their performance indicators, which should be the result of the agreement between the management and the staff.

-Effective communication within the organization: in order to foster clear understanding of the application of the philosophy.

-The application in the business sector must be gradually integrated: since the personnel in charge are not yet well-informed of the philosophy. - It is thus necessary to educate the staff and have them implement the philosophy in a purposeful manner: that the implementation should be carried out in a continuous manner and the results are followed-up.

\section{B. General details of the industrial sector samples in the survey}

Most businesses have policies on environmental management, and are highly aware of its importance. This does not come as a surprise since environmental concern has become something mandatory for every company and factory. Moreover, the majority of the samples have good knowledge and understanding of as well as positive attitude toward the application of the philosophy of sufficiency economy in the environmental management. In terms of factors contributing to success in the application of the philosophy of sufficiency economy, the most important factors are vision and policy of the management, followed by knowledge of the philosophy, staff involvement, faith in the philosophy, communication within the organization, implementation of the plan, support from relevant agencies, and follow-up on and evaluation of the implementation, respectively. 
With respect to the hypothesis test, factors contributing to the success in the application of the philosophy of sufficiency economy are the size of the industry, access to the knowledge, attitude toward the philosophy, involvement in activities related to the philosophy. It is found that;

1) Different sizes of the industry have a statistically significant relationship (0.05) with the interest in the application of the philosophy of sufficiency economy. Large-scale industries are more interested in the application thereof than middle-scale industries and smallscale industries are respectively because large-scale industries are better accommodated in various aspects, be it the budget, qualified personnel, access to the information. This is in accordance with the study of Iamnoo [2], which finds that the size of the industry has a relationship with the decision to apply for the carbon reduction label.

2) Environmental policies have a statistically significant relationship (0.05) with the interest in the application of the philosophy of sufficiency economy. Policies are important in guiding various activities, which will not be possible if policies are not transformed into implementation. This is particularly true with environmental management. Therefore, factories with policies on environmental management are more interested than those without ones in the application of the philosophy of sufficiency economy.

3) Access to the information has a statistically significant relationship (0.05) with the interest in the application of the philosophy of sufficient economy. This is in line with the research by Suphaporn Chumtong [3] on the influences of integrated marketing communication tools on the purchasing behavior of brain and memory-enhancing drink consumers in Bangkok, which finds that communication to the consumers through advertisement in both audio and video forms helps familiarize the consumers to the products and motivates them to buy them. It is also in tune with the study by the Department of Water Resources and National Institute of Development Administration NIDA [4] which finds that the community leaders' access to the information has an impact on their involvement in water resources management in an integrated manner.

4) Attitude toward the philosophy of sufficiency economy has a statistically significant relationship (0.05) with the interest in the application of the philosophy. With reference to KAP Theory [5], it can be inferred that proper knowledge and understanding of the philosophy of sufficient economy as well as proper attitude toward it will significantly affect the application thereof.

5) Experience as participants in activities related to the application of the philosophy of sufficiency economy has a statistically significant relationship (0.05) with the interest in the application of the philosophy. It can be inferred that participation in activities related to the application of the philosophy of sufficiency economy is a factor in creating a proper condition in generating interest in the application of the philosophy of sufficiency economy.

With respect to the hypothesis test, it is also found that policies on environmental management, environmental awareness, and proper knowledge and understanding of the philosophy of sufficiency economy have a statistically significant relationship (0.05) with the attitude toward the application of the philosophy of sufficiency economy. This can be summarized as follows; 1) Policies on environmental management have an impact on the attitude toward the application of the philosophy of sufficiency economy. This is in line with the study by Maisuree Issapak, Yaowanit Kittitornkul, and Sanun Pengmuen [6], which finds that facilitating factors contributing to the learning process of a household in proper solid waste management originate at school, which include the management of the school, policies on the development of the school, and the authority structure between the management and the staff 2) Environmental awareness has an impact on the attitude toward the application of the philosophy of sufficiency economy. Awareness is a cognitive process starting when an individual is influenced or driven by a stimulation, which causes that individual to learn about something. This knowledge will eventually lead to awareness and will trigger certain action or behavior in response to that stimulation, which in this context is the attitude toward the application of the philosophy of sufficiency economy.3) Knowledge and understanding of the philosophy of sufficiency economy have an impact on the attitude toward the application of the philosophy of sufficient economy in environmental management. This is in tune with KAP Theory (Roger, 1962, as quoted in Dai, Chen, Yuan and Yen, 2012) [5]. It can be inferred that knowledge and understanding have an impact on opinion and attitude; therefore, knowledge and understanding of the philosophy of sufficiency economy have an impact on the application of the philosophy of sufficiency economy in environmental management. This is also consistent with the study by Yongyut Saenpradit [7] concerning paradigm setting for community involvement in prevention of domestic violence, with the community at Bang Kayaeng, Muang District, Pathumthani as a case study. It is found that providing knowledge and understanding about the problem of domestic violence at an individual level leads to changes in knowledge, attitude, and behavior which can help prevent domestic violence.

The study also finds that the access to the information of the industrial sector has an impact on their knowledge and understanding of the philosophy of sufficiency economy. According to KAP Theory (Roger, 1962, as quoted in Dai, Chen, Yuan and Yen, 2012) [6], those who have been informed will become a factor in generating knowledge, attitude, and action in turn.

\section{The appropriate mode in applying the philosophy of sufficient economy}

With respect to the appropriate mode in applying the philosophy of sufficient economy in environmental management and other activities, the data collected through in-depth interviews of the companies or factories considered successful and as role models, and analysis of the questionnaire probing on the factors contributing to the decision in doing so of the sample group; it is found that the management is an important factor. The management must be visionary and determined in putting the philosophy into 
practice. Policies must be set in order to be the guideline for the staff, who must feel that they are involved in the implementation. Only with the staff's cooperation can continuity and sustainability of all these activities be maintained, be it through idea sharing, joint decision, joint operation and joint evaluation. Another important means to achieve sustainability is agreement between the management and the staff in setting the performance index in applying the philosophy of sufficiency economy to the practice at the staff level. Another important factor in moving the application of the philosophy of sufficiency economy ahead is faith in the philosophy, which must be inculcated in the minds of both the management and the staff. In order for faith to occur, profound knowledge and understanding must be first generated, which will in turn result in pragmatism. Of no less importance is follow-up on the results, as well as support from relevant agencies in terms of knowledge, expertise, preliminary budget and role models.

\section{CONCLUSION AND SUGgestion}

The findings of the study gained through in-depth interviews with the management or the personnel in charge of the companies and factories successful in applying the philosophy of sufficiency economy, a questionnaire surveying on the target sample group and experiment on the implementation of the appropriate mode thereof reveal that important factors contributing to success in the application of the philosophy of sufficiency economy in environmental management and other activities include concern for the well-being of the society, the management's vision and policy, knowledge and understanding of the philosophy, faith in the philosophy, staff involvement; which will lead to sustainable progress, and index performance at the individual level. Support from relevant agencies in terms of knowledge, and role model also help lead to more practical application.

\section{A. Suggestion on policies}

1) According to the 10th National Economic and Social Development Plan, though the philosophy of sufficiency economy is avidly supported, most of the cases actually put into practice are its application to the household and agricultural sectors. Therefore, there should be policies to support the application of the philosophy to the industrial sector as well.

2) At present there are only a few government agencies fostering the knowledge and understanding of the philosophy of sufficiency economy, and these agencies only do so with respect to the application thereof to the household and agricultural sectors. Therefore, there should be some relevant agencies in charge of providing the information about this.

\section{B. Suggestion on implementation}

1) Support and information provided for the application of the philosophy of sufficiency economy to the industrial sector are not yet extensive, but are mostly accessible only to large-scale businesses. Therefore, relevant agencies must continuously promote the access to the knowledge and understanding of the philosophy of sufficiency economy as well as provide examples.

2) The application of the philosophy of sufficiency economy should be simple and practical, with role models for clarity.

3) Profound understanding of the philosophy of sufficiency economy should be fostered among the management concerned in order that those in the operation understand the same things and act accordingly.

4) The application of the philosophy of sufficiency economy is not to be assessed only in terms of direct financial benefit. Other indirect benefits like better organizational morale or better environment should be put into consideration as well. For small-scale organizations, it might be necessary to put a lot of emphasis on the benefits gained in order to generate more motivation.

5) The application of the philosophy of sufficiency economy should be implemented step by step, starting from in one's daily life until it is inseparable from that person's routine. Then the application should be integrated in the work and other environmental activities. For the sustainability of the application of the philosophy in the organization, it is recommendable not to have it implemented as an activity or project to be performed out of working time.

\section{REFERENCES}

[1] Stufflebeam D.L. Evaluation Models: Viewpoints on Educational and Human Services Evaluation: Boston and Hingham, MA, 1983

[2] Iamnoo, Benjamas. Factors and Strategies in the Application for the Carbon Reduction Label. Master of Science Thesis (Environment Management), School of Social and Environmental Development, National Institute of Development Administration (NIDA), 2011.

[3] Chumtong, Suphaporn. Influences of Integrated Marketing Communication Tools on the Purchasing Behavior of Brain and Memory-Enhancing Drink Consumers in Bangkok. Sripatum Chonburi Journal. 1(1) : 63-73, 2010.

[4]. Department of Water Resources and National Institute of Development Administration. The Integrated Water Resources Management in Songkhla Lake: Watershed Area. Bangkok: National Institute of Development Administration, 2011.

[5] Rogers, E.M. 1962. Diffusion of Innovations $3^{\text {rd }}$ ed. New York: Free Press. Cited in Chien-Yun, Dai, Wan-Fei, Chen, Yu-His, Yuan and Chia-Hung, Yen. " A Study on Modification of Knowledge, Attitude and Practice on Vocational High School Electronics Courses Integrated with Nanotechnology Concept." International Journal of Thermal \& Environmental Engineering 4,1:73-79, 2012.

[6] Issapak, Maisuree., Kittitornkul, Yaowanit., and Pengmuen, Sanun. Development of the Learning Process of a Household in Proper Solid Waste Management, which Originates at School. - a Case Study at Wat Kok Samarnkoon School, Hat Yai, Songkla. Songkla Nakarin Human and Social Science Journal, 13(4), October-December 2007.

[7] Saenpradit, Yongyut. Community Involvement in Prevention of Domestic Violence - a Case Study at Bang Kayaeng. 2010. 26 June $2011<$ bttp:// www.codi.or.th/downloads/ Research/ Research01.pdf $>$. 